\title{
Managing fragmentation in global environmental governance: the REDD+ Partnership as bridge organization
}

\author{
Aarti Gupta $^{1} \cdot$ Till Pistorius $^{2} \cdot$ Marjanneke J. Vijge $^{1}$
}

Accepted: 20 March 2015/Published online: 1 April 2015

(C) The Author(s) 2015. This article is published with open access at Springerlink.com

\begin{abstract}
This article analyzes the increasing institutional and organizational complexity and fragmentation surrounding the international financing mechanism REDD+ (reducing emissions from deforestation and forest degradation in developing countries and related forest activities), now being negotiated within the UNFCCC. We focus, in particular, on critically assessing the prospects of managing such fragmentation. We do so by analyzing whether and how (what we conceptualize here as) a "bridge organization" - the voluntary, multi-stakeholder REDD+ Partnership bringing together state and non-state actors from global to local scales-has aided in managing fragmentation in this realm, through exercising four enabling functions (enhancing transparency, participation, knowledge sharing, and coordination). Our analysis shows that the REDD+ Partnership has partially succeeded in furthering such procedural aims, but that this has not resulted in a "scaling up of REDD+ action and finance," its overarching substantive aim. In contrast to dominant views of a bridge organization's modus operandi, we conclude, based on our analysis, that its value lies not in overcoming persisting geopolitical conflicts around climate mitigation and providing a "depoliticized" context within which to manage fragmentation. Instead, its success lies in permitting dialogue and exchange even in the face of persisting political conflicts over its raison d'être and functions. In making these arguments, the article extends recent debates on the prospects to manage fragmentation in global environmental governance and provides a critical assessment of the role therein for bridge organizations.
\end{abstract}

Aarti Gupta

aarti.gupta@wur.nl

Till Pistorius

till.pistorius@unique-landuse.de

Marjanneke J. Vijge

marjanneke.vijge@wur.nl

1 Environmental Policy Group, Department of Social Sciences, Wageningen University, Wageningen, The Netherlands

2 UNIQUE Forestry and Land Use GmbH, Schnewlinstraße 10, 79098 Freiburg, Germany 
Keywords Fragmentation - Climate governance - Global environmental governance · Forests · REDD+ Partnership · Bridge organization · Interaction management · Institutional interplay $\cdot$ Regime complexes

\section{Introduction}

Increasing fragmentation of the sites and sources of governance authority is now a pervasive phenomenon in the global environmental realm (Biermann et al. 2009; Zelli and Van Asselt 2013). Yet the consequences of fragmentation, and the prospects to manage fragmentation to further specified governance ends, still remain theoretically and empirically under-examined. In this article, we analyze the growing fragmentation around the issue-area of REDD,$+{ }^{1}$ an international financing mechanism currently being negotiated under the United Nations Framework Convention on Climate Change (UNFCCC). REDD+ is intended to compensate developing countries for reducing forest-related greenhouse gas emissions or sequestering carbon through forest and land-use management strategies.

The idea for such a mechanism was first introduced into UNFCCC negotiations in 2005 by Costa Rica and Papua New Guinea (for a detailed history of its evolution, see Pistorius 2012). Since then, the scope of forest-related activities to be encapsulated within it has continually expanded within the UNFCCC. It is expected that a final agreement on REDD+ will come as part of a broader global climate agreement in 2015. In the interim, debates about, and experiments relating to what REDD+ is, or should be, are underway at multiple levels of governance, driven by an ever-widening array of actors operating in varied institutional and organizational arenas.

In this article, we describe this growing institutional and organizational complexity (i.e., fragmentation) of the REDD+ issue-domain. We then analyze the extent to which the Interim REDD+ Partnership — a voluntary multi-stakeholder initiative set up by REDD+ donor and recipient countries in 2010 to "scale up action and finance" - has aided in managing fragmentation in this realm. We do so by conceptualizing the Partnership as a "bridge" organization, given its mandate to bring together, in an informal setting, the key actors, initiatives, and organizations engaged in REDD+ from global to local levels. In conceptualizing it as such, we assess what bridging functions, if any, the Partnership has exercised to date and whether, in so doing, it has succeeded in facilitating a scaling up of REDD+ action and finance. The Partnership was set up, initially, for a three-year period from 2010 to 2012, but was extended at the climate meeting in Doha in 2012 until the end of $2014 .^{2}$ Our analysis thus covers the entire period of its existence.

The REDD+ Partnership has been little analyzed in scholarly literature to date (for a few exceptions, see Reinecke et al. 2012; Pistorius and Reinecke 2013). In conceptualizing the Partnership as a bridge organization in a fragmented REDD+ landscape here, our analysis is timely, insofar as it critically engages with the notion of fragmentation management now gaining currency in scholarly analyses and because it does so for the empirical issue-area of REDD+, widely seen as one of the farthest advanced climate

${ }^{1}$ REDD+ is the UNFCCC acronym for reducing $e$ missions from deforestation and forest degradation in developing countries; and the role of conservation, sustainable management of forests and enhancement of forest carbon stocks in developing countries.

${ }^{2}$ For Partnership establishment documents and mandate, see http://reddpluspartnership.org/73943/en/. 
mitigation options now being negotiated within the UNFCCC, thus eliciting widespread interest and engagement. Our analysis draws on both primary and secondary sources, including REDD + Partnership primary documents, and participant observation of multiple UNFCCC negotiating sessions and Partnership meetings between 2010 and 2014. We also draw on 15 semi-structured interviews with both state and non-state Partnership participants over this period.

In the next section, we present relevant theoretical propositions about fragmentation in global environmental governance and the prospects to manage such fragmentation. In Sect. 3, we describe how an expanding scope of REDD+ within the UNFCCC has resulted in growing fragmentation around it, with the aim to identify the need for, and functions of, a prospective bridge organization. In Sect. 4, we analyze what bridge functions the REDD+ Partnership has executed and with what consequences for scaling up REDD+ action and finance. In conclusion, we draw out implications of our analysis for the prospects to manage fragmentation in furthering desired ends in global environmental governance.

\section{Managing fragmentation in global environmental governance}

Debates within international relations have evolved in the last decades from analyzing individual "regimes" (i.e., rules, norms, and expectations guiding behavior in a specific issue-area) to focus on "inter-linkages" between two or more regimes (Young 1996; Gehring and Oberthür 2004; Gupta 2008). In recent years, attention has focused as well on broader regime "complexes" (Raustiala and Victor 2004; Keohane and Victor 2011; Abbott 2012) and a growing "fragmentation" in global governance architectures (Biermann et al. 2009; Zelli and van Asselt 2013). These shifting debates reflect scholarly recognition of the changing nature of global (environmental) governance, with multiple arenas for public and private rulemaking, norm setting and knowledge sharing now coexisting in diverse issue-areas. Scholars are now expending much effort on mapping, and developing typologies of, such regime complexes or fragmented governance architectures, in order to further conceptual clarity and advance this research agenda (e.g., Alter and Meunier 2009; Drezner 2009; Betts 2013; Van Asselt and Zelli 2012; Orsini et al. 2013).

A prominent early definition of a regime complex was to conceptualize it as "an array of partially overlapping and non-hierarchical institutions governing a particular issue-area" (Raustiala and Victor 2004, 279). This broad definition was useful in highlighting various constitutive elements of such a complex, including "partially overlapping institutions," the need for delineation of an "issue-area," and the stipulation of "non-hierarchical" relations between constituent parts. Subsequent definitions have sought to add to, or modify, this definition. Keohane and Victor $(2011,8)$, for example, conceptualize regime complexes as "non-hierarchical but loosely coupled systems of institutions." In offering a contrasting view, Orsini et al. $(2013,29)$ suggest that the requirement of "non-hierarchical" relations is "an ambiguous and unnecessary feature" of such earlier conceptualizations and that the focus therein on "institutions" is too broad. They propose, instead, to define a regime complex as containing "three or more international regimes" with "overlapping membership" and "potentially problematic interactions." Non-problematic interactions between component parts would signal, in their view, the existence of one internally coherent regime, rather than a regime complex. 
Our aim here is not to weigh in on, or seek to resolve, such definitional differences, nor to embrace or argue for a specific terminology. Instead, we view such discussions as useful in highlighting a set of analytical concerns relating to the nature and consequences of regime complexity and fragmentation in global environmental governance. ${ }^{3}$ These analytical concerns include, inter alia, delineating boundaries around a fragmented issue-area; the need (or not) for a core within such fragmented regime complexes; and the density or number of component elements in such complexes (which could be nested, parallel or overlapping; for a detailed discussion, see Aggarwal 2005; Alter and Meunier 2006; Abbott and Snidal 2006).

As our point of departure, we view the act of drawing boundaries around an issue-area as a fundamentally political one, contingent on (contested) framings of a problem that determine what is included or excluded within a regime complex. Hence, our aim in describing growing REDD+ fragmentation in this paper is not to argue for or against a specific demarcation of this issue-area, but rather to ascertain the governance consequences of having an ever-broadening array of organizations, institutions, and actors engaged in conceptualizing and implementing REDD + at multiple levels. This approach is aligned with calls in recent literature to move beyond debating the merits or demerits of (different types and degrees of) complexity or fragmentation in normative terms, to analyzing its consequences for governance (e.g., Alter and Meunier 2009; Van Asselt and Zelli 2012; Zelli and Van Asselt 2013; see also Zelli et al. 2013).

Our primary interest, moreover, is in assessing the prospects to manage fragmentation to deliver on specific governance aims, an aspect that has been the least extensively studied thus far. In focusing on this, we also interrogate the very notion of "managing" fragmentation and thus contribute to discussions on what such management might entail and to what end. In available studies on so-called interaction management in global environmental governance, a few analysts have explored whether and how specific institutional or organizational arrangements (whether public, private or hybrid) can serve as interaction managers between component elements of a regime complex or fragmented governance architectures (e.g., Visseren-Hamakers et al. 2011; Visseren-Hamakers and Verkooijen 2013).

We extend such lines of thinking here in critically assessing the prospects for, and means of, managing fragmentation in the REDD+ arena, through the Interim REDD+ Partnership. In so doing, we draw on and adapt to our case a useful typology of (institutional) interplay management developed by Oberthür (2009). In this typology, Oberthür distinguishes between levels and modes of interplay management. According to him, the first, highest, level of interplay management is through an overarching institution, whereby “... a new specialized overarching institution ... engage[s] in decision-making beyond the interacting institutions" (pp. 375-376). A second level is joint interplay management through "active targeted efforts to coordinate activities of the interacting institutions [and] conscious creation of horizontal structures for coordination" between two or more interaction institutions (p. 376). A third, lowest level consists of unilateral management by individual institutions through "independent collective action and decision-making within one or more of the interacting institutions without coordination between them" (p. 376).

Added to these three levels are two modes of interaction management: regulatory and enabling. Regulatory interplay management, according to Oberthür, focuses on "prescribing, proscribing or permitting certain behavior" with the possibility to also implement and enforce such prescriptions. Such an interaction management mode resonates with

$\overline{3}$ We use the terms "regime complex" and "fragmentation" interchangeably here. 
"hierarchical, regulatory, top-down, coercive, and command-and-control approaches" to global environmental governance (Oberthür 2009, 377). A second mode is enabling interaction management, which works through learning and capacity building, and focuses not on prescribing behavior, but on communication and knowledge brokering as a way to persuade, and enhance capacities to negotiate and implement (shared) governance goals. This latter mode of interaction management resonates with "non-hierarchical, communicative, voluntary and capacitating/enabling governance approaches" (p. 377).

The above typology provides us with a starting point from which to characterize the level and mode of fragmentation management likely to be at play in our case. First, since the REDD+ Partnership was explicitly intended to play a facilitative and knowledgebrokering role, we assume that it functions in an enabling rather than regulatory mode of interaction management, as per the typology above. In terms of levels of interaction management, however, our case does not fit any of the three identified by Oberthür. The REDD+ Partnership is not envisioned to function as an overarching institution (or organization) above relevant others, nor one that jointly with another co-coordinates horizontally across an institutional landscape. Nor is it an individual entity exercising decisionmaking authority by itself, without coordination with relevant others. Instead, we conceptualize the REDD+ Partnership here rather as a bridge organization, linking across actors and levels, one that is hierarchically sub-ordinate to the UNFCCC, but links UNFCCC policymakers to sub-national and local (public and private) actors active in REDD+.

Conceptualized as such, we view the Partnership as a site of interaction between global and local scales and state and non-state actors engaged in REDD+ debates and actions. Our characterization of the Partnership as a "bridging" entity intended to manage fragmentation is, to our knowledge, novel within global environmental governance literatures. In developing our conceptualization further, we thus also draw here briefly on writings within organizational and environmental management, adaptive governance, and social learning, where the notion of a "bridge organization" has been more extensively discussed (e.g., Cash et al. 2006; Crona and Parker 2012; McMullen and Adobor 2011). A bridge organization is generally understood in such writings as, inter alia, "a forum for the interaction of...different kinds of knowledge and the coordination of ...tasks that enable cooperation: accessing resources, bringing together different actors, building trust, resolving conflict, and networking..." (Berkes 2009, 1692). Such organizations can "respond to opportunities, [and] serve as catalysts and facilitators between different levels of governance and across resource and knowledge systems" (Berkes 2009, 1695; see also Folke et al. 2005). Our conceptualization of the Partnership, as serving as a bridging entity in a fragmented REDD+ governance landscape, is akin to such a view of a bridge organization.

In characterizing the Partnership as such, however, our intent is also to subject the very notion of such bridging to critical scrutiny. As a recent analysis of bridging organizations in adaptive resource governance emphasizes, “...little is known about the conditions that foster learning .... and how, specifically, bridging organizations facilitate this process. One reason is that the concept of bridging organizations, as well as the actors, social groups, and collaborative processes involved in them, remains poorly articulated" (Crona and Parker 2012, 32). Our aim is thus to further understanding of such processes, as well as their role in global environmental governance. We do so by analyzing whether the REDD+ Partnership has exercised a variety of enabling, bridging functions as a means to manage fragmentation in this realm and if its enabling mode of fragmentation management has helped to further its substantive aim of scaling up REDD+ action and finance. 
We turn next to describing how the scope of REDD+ has expanded within the UNFCCC, and the growing institutional and organizational fragmentation resulting from this.

\section{Increasing REDD+ fragmentation: role for a bridge organization?}

The UNFCCC acknowledged the role of forests as sinks and sources for greenhouse gas emissions early on, yet its Kyoto Protocol focused only on mitigation options relating to forest carbon stocks in developed countries. Reducing emissions from deforestation in developing countries came to the fore only in 2003, when Brazilian scientists introduced the concept of "compensated reduction" of deforestation into UNFCCC debates. This had coalesced by 2005 into negotiating a financial mechanism to compensate developing countries for "reducing emissions from deforestation" (RED), and by 2007 into REDD (reducing emissions from deforestation and forest degradation). By 2009, a "+" was added to REDD, to include conservation of forest carbon stocks, sustainable management of forests, and enhancement of forest carbon stocks in developing countries. This expanded scope was pushed for by those countries (such as India and China) that had increasing rather than decreasing forest cover, yet also wanted to participate in this mechanism (for a history of REDD+ negotiations within the UNFCCC, see Pistorius 2012).

This continually expanding scope of forest-related activities under REDD+ has significantly increased the political and technical challenges inherent in converting it into a workable reality. These challenges include, inter alia, the need to develop adequate monitoring, measuring, reporting, and verification (MRV) systems to document forest carbon changes across such a diverse range of activities (Herold and Skutsch 2011; Visseren-Hamakers et al. 2012a; see also Gupta et al. 2012, 2014), as well as the need to ensure that an expanded REDD+ delivers not only carbon, but also "non-carbon" benefits (relating to biodiversity and social aspects) (McDermott et al. 2012; Visseren-Hamakers et al. 2012b). UNFCCC decisions on these and other aspects of operationalizing REDD+ are contained in the 2013 "Warsaw Framework on REDD+" (UNFCCC 2013). Further agreements include a three-phased approach to REDD+ implementation: a first "readiness" phase (including developing national REDD+ strategies); a second demonstration phase; and a third results-based financing phase.

A growing institutional and organizational complexity around REDD+ has accompanied these policy developments within the UNFCCC, as we sketch briefly below, relating to REDD+ readiness and financing, as well as non-carbon benefits or safeguards.

\subsection{REDD + readiness and finance}

Being ready for REDD+ requires countries to develop national REDD+ strategies, as well as forest monitoring and MRV systems. Such readiness activities have thus been underway in many developing countries over the last half decade, accompanied as well by extensive experimentation with REDD+ pilot projects on the ground. All of these elements have required capacity building and financial support, and such support has come, increasingly, from a proliferating variety of multilateral, bilateral, and public-private sources, operating at multiple scales. The multilateral initiatives offering such support include, most prominently, the World Bank Forest Carbon Partnership Facility (FCPF) and Forest Investment Program (FIP), as well as the UN-REDD Programme, established jointly by FAO, UNEP, 
and UNDP. Also active here is the Global Environment Facility (GEF). The FCPF and UNREDD have each disbursed significant multilateral funding for REDD+ readiness activities, including for capacity building and design of national REDD+ strategies, as well as development of national forest monitoring and MRV systems. Bilateral support for such activities has been forthcoming from, among others, the Norwegian Agency for Development Cooperation (NORAD) Climate and Forest Initiative, and the German International Climate Initiative (Cerbu et al. 2011; Davis and Daviet 2010).

With regard to MRV systems, guidelines for these were initially negotiated within the UNFCCC's Subsidiary Body for Scientific and Technological Advice, which in turn drew upon the Intergovernmental Panel on Climate Change (IPCC)'s good practice guidelines for forest carbon emissions relating to land use and land-use changes (IPCC 2003). The REDD+ Warsaw Framework now provides guidance on establishing such systems, yet allows countries considerable freedom to (differently) interpret and apply its general provisions. As such, multilateral organizations and bilateral agencies have adopted sometimes similar and sometimes diverging approaches to providing support for these activities, ensuring a growing need for coordination among such sources of support (Davis and Daviet 2010). Furthermore, the REDD+ MRV systems to be developed have themselves become ever more complex, given the expanded scope of forest-related activities now covered by this mechanism. This also suggests a need to identify and share information about best practices relating to developing and implementing such systems in diverse national contexts.

Such readiness activities have also been accompanied by extensive experimentation with REDD+ pilot projects on the ground (Wertz-Kanounnikoff and Kongphan-Apirak 2009; Cerbu et al. 2011). Again, multilateral and bilateral donors, as well as an array of public-private initiatives, are now involved in supporting such pilot projects. The latter include non-governmental organizations, such as the World Wildlife Fund (WWF), as well as companies seeking to offset their carbon emissions or invest in such projects for reasons of corporate social responsibility (Streck 2012).

These developments have proceeded, furthermore, in a context where contentious debates are still underway (within the UNFCCC and beyond) on whether REDD+ is to be supported by fund- or market-based financing, as well as what the modalities and disbursement options for such financing should be. REDD+ financing discussions within the UNFCCC have progressed more slowly than have debates on "technical" components of operationalizing REDD+ (relating to forest monitoring and MRV systems, and safeguards) (Streck 2012). In this context, current financing for the different phases of REDD+ is coming from a plethora of actors and organizations. While the bulk of REDD+ financing to date consists of bilateral and multilateral support for the first phase of REDD+ "readiness," market-based funders of the various REDD+ phases and activities have also rapidly emerged. These include, for example, regional and sub-national carbon market initiatives exploring options to include REDD+ credits as offsets in voluntary carbon markets (Streck 2012; Visseren-Hamakers et al. 2012b). Many of these initiatives have also taken the lead in developing standards for accrediting carbon credits generated by REDD+ pilot projects. These include, inter alia, the Verified Carbon Standard (VCS), Plan Vivo, and the Gold Standard. These standards are, however, now in fierce competition, due to their considerable overlap (Moss et al. 2011). 


\subsection{Non-carbon benefits and safeguards}

The above developments are related, as well, to another key element of REDD+ implementation: the links between carbon and non-carbon benefits (including biodiversity and social aspects) to be secured through REDD+. This link has brought a whole slew of new actors, from the biodiversity and nature conservation communities, but also from local community groups, into the REDD+ institutional and governance landscape. With regard to climate-biodiversity links, the Convention on Biological Diversity (CBD) has set up, for example, an Ad Hoc Technical Expert Group on biodiversity and climate change to assess potential impacts of REDD+ on its own objectives. The CBD secretariat has also made several submissions and facilitated side-events at UNFCCC meetings on the issue of biodiversity co-benefits under REDD+ (Pistorius 2012; CBD 2015). At the CBD meeting in Hyderabad in 2012, countries agreed on voluntary guidance to monitor the impacts of REDD+ on biodiversity. Although these CBD initiatives have progressed with clear recognition of the UNFCCC as the hierarchical node in an expanding REDD+ governance landscape, the very different governance objectives of each regime makes collaboration between them a contested issue, one on which there is very little consensus.

The UNFCCC's own discussions on non-carbon benefits or REDD+ "safeguards" have meanwhile also yielded general guidelines on the need for countries to develop so-called safeguard information systems, as part of the 2013 Warsaw Framework. However, countries can interpret what such safeguard information systems should look like, in line with their national priorities (McDermott et al. 2012; Visseren-Hamakers et al. 2012b). As such, multiple organizations and actors are now also weighing in to interpret, or give substance to, the notion of safeguards. For example, a number of private (and potentially competing) REDD+ environmental and social safeguard certification schemes now exist, with various organizations also helping to establish systems to measure, report and verify non-carbon benefits of REDD+ activities (in addition to carbon-related outcomes). Such initiatives include the REDD+ Social and Environmental Standards, developed by a public-private initiative that includes the Climate, Community and Biodiversity Alliance (CCBA), CARE International, and some REDD+ governments, and the World Bank's Strategic Environmental and Social Assessment (McDermott et al. 2012).

In sum, the growing institutional and organizational complexity around REDD+ is linked to its ever-increasing scope within the UNFCCC. Such fragmentation is reflected in the multiple interpreters of UNFCCC REDD+ rules and guidelines for its component elements, operating at multiple levels. This is evident in the proliferating sources of support, including capacity building and funding, for REDD+ readiness and demonstration activities; in the potentially competing interpretations of certification standards for assessing (carbon and non-carbon) results; and, more broadly, in the growing number of public and private actors at multiple levels jostling to define, operationalize and experiment with REDD+. While the core impetus for such activities is still anchored firmly within the UNFCCC, a multiplicity of actors and organizations now seek to support, interpret, and implement the policy decisions relating to REDD+ within the UNFCCC.

With regard to "scaling up action and finance" for REDD+ then, we can surmise that this growing complexity offers both challenges and opportunities, thereby ostensibly opening up space for a potential bridge organization to leverage opportunities and help mitigate the challenges. The potential opportunities include generating (desirable) competition, and a race to the top for best practices, as well as incentivizing innovative approaches and experimentation on all elements, and in all phases, of operationalizing 
REDD+. Challenges, on the other hand, include potential inefficiencies or duplicative use of scarce resources, high transaction costs, or confusion regarding the plethora of approaches to MRV and certification standards now available.

As such, a fragmented REDD+ governance arena provides fertile ground for a bridge organization to serve as a site for multi-stakeholder interactions across vertical and horizontal scales, and to exercise a variety of enabling functions. We turn next to analyzing whether and how, and with what consequences, the REDD+ Partnership has played such a role.

\section{Managing fragmentation through the REDD+ Partnership?}

As one reaction to the widely perceived "failure" of the 2009 climate meeting in Copenhagen to agree to a successor climate agreement to the Kyoto Protocol, several Parties to the UNFCCC sought ways to at least advance the REDD+ agenda globally. In line with this, 50 countries met in March 2010 in Norway to establish the (Interim) REDD+ Partnership. The Partnership was explicitly designed to be inclusive of all interested countries (both potential REDD+ donors and recipients, called Partners), as well as non-state stakeholders, with the overarching aim to scale up action and finance (REDD+ Partnership 2010a; Reinecke et al. 2012).

The declared core objective of the REDD+ Partnership was:

“...to contribute to the global battle against climate change by serving as an interim platform for the Partners to scale up REDD+ actions and finance, and to that end take immediate action, including improving the effectiveness, efficiency, transparency and coordination of REDD+ initiatives and financial instruments..." (REDD+ Partnership 2010a, 1).

In so doing, the Partnership stated also its aim to be "inclusive of all committed countries as well as representatives of relevant stakeholders including indigenous peoples, local communities, civil society and the private sector" (Partnership 2010a, 2).

Given these objectives, and drawing on our discussion of a bridge organization in Sect. 2, we distill here four bridging, enabling functions that the Partnership has sought to exercise, as a way to manage fragmentation in this realm and meet its substantive aim of scaling up REDD+ action and finance. These functions include, first, enhancing transparency around REDD+ actions and finance, as a way to understand who is supporting what and what (unmet) needs exist; second, enhancing participation, i.e., multi-stakeholder engagement and input into REDD+ discussions; third, building trust and enhancing knowledge sharing, as a means to identify best practices, and thereby help facilitate a scaling up of such practices; and fourth, enhancing coordination, both vertical and horizontal, of REDD+ actions and finance, in order to leverage synergies and avoid duplication in this realm.

In exercising such bridging functions, the Partnership explicitly subordinated itself to the UNFCCC in its founding documents. Except for issue-specific workshops held irregularly, the main Partnership meetings (at least two per year) have been organized backto-back with UNFCCC meetings, given that most Partners are also UNFCCC REDD+ negotiators. Two co-chairs are selected from the 75 Partner countries (one each from a developed and developing country) to chair the Partnership for non-renewable terms of 6 months each. The co-chairs are responsible for proposing an agenda and activities for 
their term. UN-REDD and the World Bank's FCPF jointly host the Partnership Secretariat, which is responsible for organizing Partnership meetings, and helping to execute its multiyear work program.

We turn next to assessing whether and how the Partnership has exercised the four bridging, enabling functions of enhancing transparency, participation, knowledge sharing/ trust building, and coordination identified above, and whether and how such functions have contributed to meeting the overarching aim of "scaling up REDD+ action and finance."

\subsection{Managing fragmentation: Enhancing transparency?}

Perhaps most directly related to the Partnership's substantive objective of "scaling up action and finance" is a focus on enhancing transparency about such actions and finance. In order to fulfill this aim, the Partnership created two instruments to share and disseminate information about REDD+ actions and financing: the Partnership website and the so-called Voluntary REDD+ Database (VRD). The VRD, in particular, has been one of the most visible and concrete outputs of the REDD+ Partnership. It consists of a database of REDD+ financial flows and relies upon a so-called dual-input procedure by which to gather information, whereby donors report on the REDD+ funding amounts disbursed (and to whom) and beneficiary countries report on funding received. Countries submit information to the Partnership Secretariat, which inputs it into, and maintains, the VRD.

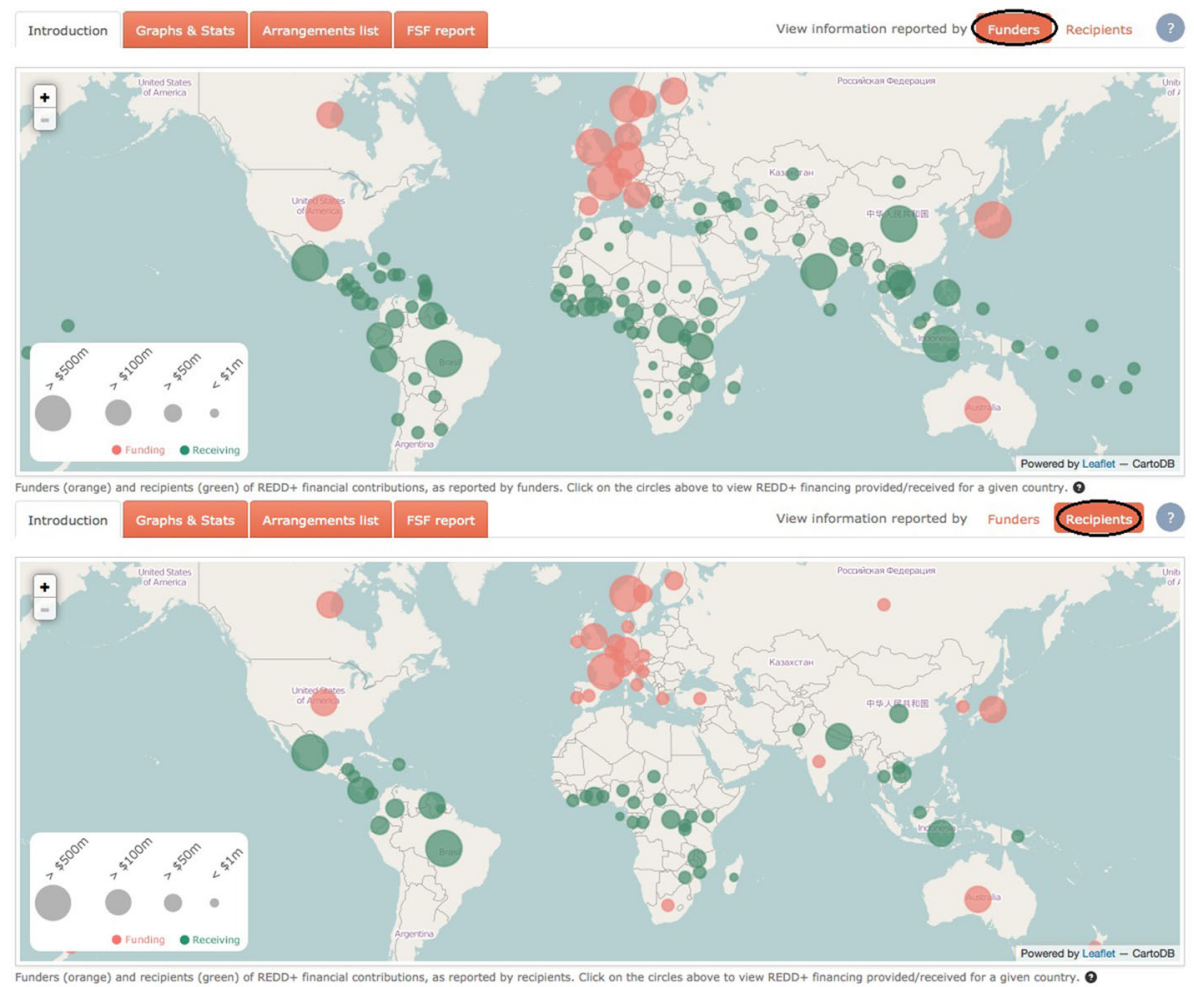

Fig. 1 Transparency about REDD+ financing as reported by funders (above) and recipients (below). Size of circles indicates the amount of funding (retrieved from http://www.fao.org/forestry/vrd/, March 25, 2015) 
One of the most noteworthy results of this exercise has been a striking discrepancy between the funding amounts reported by donors and recipients. At the time of writing, donor countries reported that they have disbursed US\$ 7.59 billion in bilateral and multilateral funding for REDD+, of which US\$ 5.98 billion has been transferred, or pledged, to specific REDD+ countries. Recipient countries reported, however, a total sum of US\$ 4.68 billion, of which US $\$ 2.25$ billion has been transferred or pledged to specific countries (see Fig. 1).

These discrepancies have led to some heated discussions in Partnership meetings between donor and recipient countries, with regard to explanations for the mismatch. These explanations include, inter alia, that donor amounts include both disbursed and pledged funds, while recipient countries report only what they have actually received. More importantly, some donor figures include broad forestry-related development aid funding, rendering the boundaries around what constitutes "REDD+ finance" (and, related to that, "REDD+ actions") fuzzy. On the recipient side, the discrepancy is also explainable by the fact that those required to provide information to the VRD (usually UNFCCC REDD+ focal points within a specific country) may not be aware of funds received by other arms of the government or may not have the resources or capacity to collate and report on received funding or to distinguish between general forestry versus REDD+ specific funding. ${ }^{4}$

Notwithstanding ongoing efforts by Partners and the Secretariat to understand the causes for, and take steps to reduce, the mismatch in reported donor and recipient amounts, this exercise has arguably yielded one of the most valuable outputs of the REDD+ Partnership's bridging efforts to date. It has clearly highlighted that the aim of objectively laying bare, or making transparent, what has been disbursed, by whom, to whom, and for what purpose, is much more complex than assumed. The discrepancy in donor and recipient reporting reveals, instead, that there are very diverse perspectives on what constitutes REDD+ actions and finance in the first place and who (should) determine this. The VRD has thus made clear that the nature and sources of REDD+ financing (and related to that, REDD+ actions) are neither clear, nor widely shared, among countries.

It is unlikely, furthermore, that these inherently political issues can be fully resolved through providing "more and better" information to the VRD (as very often called for in this context), since different interpretations of what is "more and better" information, and whose information is valid, persist, regardless of enhanced national capacities to gather data, or technical improvements in inputting data. While such improvements can certainly be sought, the discrepancies suggest that in such contested areas of global environmental governance, transparency itself is often a site of political conflict (Gupta 2010a, b) and can be constitutive of that which it seeks to make transparent. ${ }^{5}$ This is in contrast to a dominant view of transparency as a value-neutral means by which to reveal an objective "reality" (in this case, about REDD+ financing), in order to facilitate more rational decisions.

The consequences of the enhanced transparency provided by the VRD for the Partnership's substantive aim of "scaling up action and finance" remain to be seen and are linked to a broader question about whether consensual understandings of what constitutes REDD+ (or REDD+ finance) are even necessary for such a scaling up to occur. Meanwhile, at the final meeting of the Partnership in November 2014 in Lima, the Partners

\footnotetext{
4 Participant observation during REDD+ Partnership meeting, June 9, 2014, Bonn; Interview with a programme officer at the UN-REDD Programme, 2-12-2014.

5 For a detailed analysis of the politics of making REDD+ transparent, see Gupta et al. (2012, 2014).
} 
agreed to continue the VRD for another 2 years beyond the end of the Partnership itself. This signaled that its dual-input approach to reporting on REDD+ financial flows was acknowledged to be useful by all, even as it revealed conflicting rather than consensual views on the first-order question of what constitutes REDD+ action and finance.

\subsection{Managing fragmentation: Enhancing multi-stakeholder participation?}

In addition to fostering transparency about REDD+ actions and finance, the Partnership also aimed to be inclusive of a wide array of relevant stakeholders. Again, as with enhancing transparency, the Partnership has provided a valuable experimental setting in which to ascertain the possibilities and challenges of securing enhanced and meaningful multi-stakeholder participation in contested areas of global environmental governance. The experiment has highlighted at least three challenges. These include: first, whether any stakeholders are at the table (and the political and logistical constraints that might incentivize or disincentivize this); second, whose voices are present and being heard; and third, how representative these voices are, i.e., who speaks for whom. All of these aspects shape the nature and significance of multi-stakeholder involvement in this setting, and its contribution, if any, to the Partnership's overall aim of scaling up action and finance.

With regard to whether any stakeholders were engaged at all, the early meetings of the Partnership in 2010 were overshadowed by major disputes about how inclusive it should be (Davis and Daviet 2010). As a result of such disputes, initial Partnership meetings were closed to stakeholders, even though a broad array of civil society groups and private actors active in REDD+ had enthusiastically welcomed the Partnership's establishment, and the opportunity to engage in an informal setting with REDD+ negotiators. While most REDD+ Partner countries pushed for the multi-stakeholder character of the Partnership to be reinstated in these early months, a few countries blocked this, ostensibly, as some have speculated, because of concern that multi-stakeholder presence could result in a shift of the Partnership's focus from a scaling up of finance to issues such as safeguards (e.g., Lang 2010a).

Following an inability to effectively participate in the Partnership in its initial discussions, 35 non-governmental organizations wrote a letter to the co-chairs in September 2010 to "reiterate [their] disappointment with the protracted lack of political will to ensure proper participation of civil society and indigenous peoples' organisations in the processes of the Interim REDD+ Partnership" (Lang 2010b). The issue was only resolved with a change in Partnership co-chairs after the first 6 months (REDD+ Partnership 2010b). ${ }^{6}$ Meetings since then have been multi-stakeholder as intended, and the input of stakeholders and experts at technical workshops has been particularly welcomed. However, criticism and debate about whether such interaction is adequate, meaningful, and representative remains. A key indicator for the possibility of meaningful engagement is the timeliness with which information about meeting dates, agendas, and draft work programs is provided to stakeholders. This has proven to be a consistent challenge and source of complaints from stakeholders. During development of the most recent (2013/2014) Partnership work program, for example, stakeholders were only belatedly given an opportunity to comment, but with lack of time and conflicts over the meeting agenda, their possibilities for input were negligible. Such experiences led some to question the added value of continued par-

\footnotetext{
${ }^{6}$ Interview with representative of DG Climate, European Commission, November 2012, Doha.
} 
ticipation in the Partnership, with interest in doing so declining over time (Lang 2010a, b, 2014).

Additional challenges included a lack of resources to travel to meetings, especially when these were not held back-to-back with the UNFCCC. In response to a significant decline of stakeholder participation in meetings by 2012, the Partnership agreed to finance two non-state representatives from each region (one civil society, one indigenous community representative) to attend its meetings. ${ }^{7}$ While this did secure some additional stakeholder participation, it raised issues of representation: whether the right person was at the table, and whom they purported to speak for. Such issues of inclusion and representation constitute long-standing debates in multilevel environmental governance, yet the Partnership experience reiterates that simply securing a seat at the table does not necessarily constitute meaningful engagement.

Where stakeholder engagement has been seen as very valuable is in furthering the third Partnership enabling function of enhancing knowledge sharing, to which we turn next.

\subsection{Managing fragmentation: Enhancing knowledge (and trust)?}

In addition to enhancing transparency and participation, knowledge and experience sharing was widely seen as another crucial enabling function, with the aim to facilitate collective learning, enhance trust, and thereby facilitate the scaling up of REDD+ action and finance. Such a knowledge sharing function was explicitly intended to build capacity among REDD+ negotiators to discuss complex and interlinked REDD+ issues under negotiation within the UNFCCC, as well as to share best practices in operationalizing REDD+ in national and local contexts on the ground.

To execute this latter knowledge sharing and collective learning function, the Partnership relied upon a series of thematic, so-called technical workshops, organized during regular Partnership meetings. Topics covered at these sessions included MRV systems; development of "forest emission reference levels," i.e., benchmarks against which REDD+ emission reductions/savings are to be assessed; sources and modes of financing; or development and assessment of non-carbon benefits. Participants in these workshops included Partner countries and other stakeholders, as well as invited external experts.

One interesting dynamic from such activities was to trigger, in some instances, a "race to the top" in experimenting with innovative approaches to operationalizing REDD+ in diverse national contexts. Oft-noted examples include a wide sharing of Guyana's approach to institutionalizing and reporting on safeguards, or Indonesia's readiness efforts and governance reforms (Reinecke et al. 2012), whereby a sharing of experiences helped to stimulate the dissemination of such "best practices" to other contexts (Pistorius and Reinecke 2013, see also La Viña and Lee 2014). Knowledge sharing thus enabled the Partnership to function as a "competitive REDD+ marketplace," whereby REDD+ countries could assess interest and alignment of priorities with specific donors, while displaying innovative approaches. As such, the Partnership's knowledge sharing function has been unanimously seen as helpful. In this, it has indeed served as a bridging entity, bringing actors in a fragmented governance landscape together to enhance collective learning. In acknowledging its utility, the final Partnership meeting in November 2014 in Lima reiterated the need to identify other fora for knowledge exchange, particularly focusing on national-level REDD+ implementation (REDD+ Partnership 2014).

\footnotetext{
7 Interview with a member of the UN-REDD Secretariat staff, December 2, 2014.
} 
Regarding the related aim of enhancing trust and facilitating progress in UNFCCC negotiations, the extent to which the Partnership has facilitated this remains contested. As one interviewee put it, the Partnership helps to build "trust and understanding... At least... [for] agreeing on the terminology around REDD+ and also kicking around new concepts, I think it's useful." 8 Another stated that "the longer and the more you....share information and $\ldots$ understand the positions of others, the ... closer we may come to a final breakthrough [in the UNFCCC]." 9

A key advantage offered by the Partnership setting in this regard was its exclusive focus on REDD+, with participation limited to those with a stake in this issue, or as an interviewee put it, for the "coalition of the willing" ${ }^{10}$ to engage. This is in contrast to REDD+ discussions within the UNFCCC, where 195 countries negotiate a plethora of partly linked agenda items under extreme time pressure, with REDD+ sometimes becoming a bargaining chip to secure other desired outcomes for countries with little or no interest in it. The Partnership meetings brought together instead those UNFCCC representatives negotiating specifically on REDD+, yet in a setting widely proclaimed to be "not a negotiation body" but rather "a platform where people can... talk openly, freely... without any limitations."11

The Partnership was also described as not "clouded by diplomacy" 12 but able to operate "in isolation of" the UNFCCC negotiations. ${ }^{13}$ For some, this did indeed serve to enhance trust among Partners, since negotiators could "share in a more frank way their view$\mathrm{s}, \ldots$ [and] try to come up with solutions that can be satisfactory for all..., [as a way] to simply speed up..." the UNFCCC negotiations. ${ }^{14}$ Others noted, however, that countries that most often dominated discussions and outcomes in the UNFCCC were also shaping discussions in the Partnership. One interviewee argued, for example, that there was "way too much...overlap between the regular negotiators at the UNFCCC and the people sitting at the REDD+ Partnership" causing people to "automatically jump back to negotiation mode." 15 Such a negotiation mode hindered, according to some, the open and free exchange of ideas, and enhancing of trust.

Yet others noted, however, that the desired informal, "non-political" mode of the Partnership was unrealistic from the start. As a Greenpeace representative put it, "...politics, it seemed, was ostensibly to be left outside, so REDD+ could be reduced to a seemingly technocratic and harmonious discussion among family and friends" (Ritter 2012). This mirrors a conclusion we draw from this and other aspects of the Partnership's functioning, that a bridge organization's enabling functions cannot (and indeed, should not seek to) be executed in a "depolicitized" manner, as many continue to call for (e.g., La Viña and Lee 2014), in order to provide value in a contested global environmental governance context.

\footnotetext{
8 Interview with representative of DG Climate, European Commission, November 2012, Doha.

9 Interview with first representative of WWF international, 2011.

${ }^{10}$ Interview with representative of CfRN, 12 June 2014, Bonn.

11 Interview with representative of German Ministry of the Environment, 2011.

12 Interview with programme officer at the UN-REDD Programme, 2-12-2014, via Skype.

13 Interview with representative of DG Climate, European Commission, November 2012, Doha.

14 Interview with first representative of WWF international, 2011.

15 Interview with observer of the Partnership, 8-02-2012.
} 


\subsection{Managing fragmentation: Enhancing coordination?}

Finally, the REDD+ Partnership aimed not only to enhance transparency, participation, knowledge sharing, and trust, but also greater coordination (both vertical and horizontal) between REDD+ actors, institutional and organizational entities active at different levels. A few examples of such potential coordination are briefly discussed here. First, and in a horizontal context, there were initial hopes that the Partnership would facilitate discussions between the UNFCCC and the CBD on REDD+ safeguards. Second, through the sharing of experiences and emerging best practices mentioned above, the Partnership also aimed to encourage South-South partnerships and private-public partnerships to facilitate REDD+ implementation on the ground. Third, in requiring the Partnership Secretariat to be jointly managed by the two main REDD+ multilateral financing bodies, the World Bank's FCPF and UN-REDD, the Partnership early on signaled the importance of greater coordination between these entities, as one way to counteract visible fragmentation in the REDD+ issue-domain.

While closer engagement with the CBD did not materialize to the extent that some may have hoped, given conflicts over priorities and primary objectives of the biodiversity and climate regimes, ${ }^{16}$ increased South-South partnerships have been fostered (La Viña and Lee 2014). With regard to coordination of REDD+ multilateral funding entities, while the joint Secretariat has been important, coordination between the UN-REDD Programme and the World Bank's FCPF is already underway in other settings, including through joint meetings of the two initiatives, suggesting that the Partnership alone is not instrumental here (see footnote 16). An area where understandings (between donor and recipient countries) on coordination continue to diverge, furthermore, is whether such coordination is most needed at the multilateral (donor) level or at the national level within REDD+ recipient countries, with donors arguing for the latter as the most pressing need.

Thus, while enhancing coordination between actors, organizations, and institutions engaged with REDD+ at multiple levels has been sought through the Partnership, such coordination has been difficult to foster in practice, making this one of the hardest bridging aims to fulfill. This is linked to a well-known lack of incentives to coordinate and be coordinated, and lack of clarity regarding who benefits from (what kind of) coordination in global environmental governance. In the REDD+ context, how enhanced coordination at various scales may (or may not) contribute to scaling up of REDD+ action and finance is now a topic under intense discussion within the UNFCCC itself, under its agenda item on coordination of support and (new) institutional arrangements for REDD+.

\section{Conclusion}

We have argued in this paper that the institutional and organizational complexity (i.e., fragmentation) around REDD+ is rapidly increasing, stimulated in part by its expanding scope within the UNFCCC. The UNFCCC remains the (hierarchical) core in a fragmented REDD+ governance architecture, insofar as it establishes the normative and regulatory framework with which all other actors, institutions, and organizations have to contend. Nonetheless, there are large degrees of freedom in doing so, given the general nature of its guidelines and provisions. As a result, there is a potential to produce diverging REDD+

16 Interview with member of UN-REDD/Partnership Secretariat, December 2, 2014. 
realities in different contexts, with implications for a coordinated scaling up of REDD+ action and finance.

Our analysis hence considered whether and how the REDD+ Partnership, established to fulfill a variety of enabling, bridging functions in this fragmented landscape, has functioned to date and whether it can be said to have "managed" fragmentation, in order to further specified governance aims. We focused, in particular, on its functions relating to enhancing transparency, participation, knowledge sharing and coordination and assessed whether these have facilitated the "scaling up of REDD+ action and finance."

As outlined in the previous section, the Partnership has partially fulfilled each of these four enabling, bridging functions, with implications for its overall impact.

With regard to enhancing transparency, the Partnership's efforts have revealed discrepancies in understandings between donor and recipient countries regarding what constitutes REDD+ actions and finance. Countries have decided, nonetheless, that the VRD will continue beyond the lifetime of the Partnership, implying that it may become an important input into future UNFCCC deliberations on REDD+ financing. If so, our findings in this regard are important: they imply that the utility of enhancing transparency does not (solely or necessarily) lie in securing an "objective" reporting of "facts" that will reveal the uncontested "reality" of REDD+ financing and thereby facilitate more rational decisions, as is often assumed. Instead, the VRD's case shows, as do other examples of "governance by disclosure" in the global environmental realm, that whose information counts (and what is to be made transparent) is often a site of political conflict.

With regard to enhancing participation, our analysis revealed that securing meaningful multi-stakeholder engagement is essentially, and inevitably, a political process. Many stakeholders have become disillusioned in their attempts to participate in the Partnership, because of a realization that, despite its informal voluntary setting, meaningful impact is only marginally more feasible here, as compared to the UNFCCC. As with enhanced transparency, enhancing meaningful multi-stakeholder engagement, as another bridging function, thus remains subject to the broader geopolitical conflicts around REDD+.

With regard to enhancing knowledge and trust, our analysis suggests that many have seen the Partnership as a useful forum to enhance knowledge sharing about REDD+ and thereby also facilitate UNFCCC deliberations. Others have viewed the hierarchical ties between the UNFCCC and the Partnership as too strong to prevent a spillover of the interests and practices from the UNFCCC to the Partnership. This notwithstanding, our analysis implies generally that knowledge sharing and collective learning can be enabled even in the absence of trust. If collective learning is occurring, it is occurring in the face of persisting political contestation and potentially divergent interpretations of what is being learned. Yet this renders such learning potentially even more valuable.

With regard to enhancing coordination, the Partnership has been credited with facilitating South-South collaborations in REDD+, yet coordination between diverse multilateral regimes, such as the UNFCCC and the CBD, or between multilateral funding entities, has been harder to incentivize.

More broadly, we conclude from the partial fulfillment of the four bridging functions analyzed here that each is subject to the same political conflicts and dynamics that shape REDD+ deliberations in any other setting. Having an ostensibly informal, voluntary, enabling and bridge-building setting does not, and cannot, transcend the structural dynamics and geopolitics underpinning collective attempts to tackle climate change, wherever these occur.

This is most clearly reflected, perhaps, in the persisting conflicts over how to interpret the Partnership's overarching objective to "scale up actions and finance." In the debate on 
extending the Partnership during the 2012 climate conference in Doha, the Coalition of Rainforest Nations (CfRN) consisting of approximately 70 tropical countries that negotiate as a block within the UNFCCC, argued that scaling up REDD+ actions and finance meant that the Partnership activities should directly result in increased flows of funding. They called for reaffirmation of this primary objective of the Partnership for the period 2013-2014 and voiced their disappointment about the Partnership's achievements to date in this regard. ${ }^{17}$

Others, in particular donor countries, reiterated their understanding that the Partnership's aim to scale up action and finance was to be understood as enhancing transparency about existing actions and finances, as a means to assess gaps and identify needs, which could then trigger additional action (including funding), also in other settings. As a recently concluded assessment of the Partnership notes, "Assessing this goal [of scaling up action and finance] was challenging due to lack of shared understanding, or interpretation, of what the objective meant and entailed" (La Viña and Lee 2014, 2, see also Lang 2014).

With regard, then, to our theoretical interest in fragmentation and its management, and the role of bridge organizations therein, our analysis suggests that the overarching normative structures and political dynamics shaping global (environmental) governance not only shape the nature and consequences of fragmentation, but also any attempts to manage it. As we have shown, the goals of fragmentation management, and hence the functions of bridge organizations, remain subject to political contestation, multiple interpretations and negotiation. The differences in understandings of the core objective of the REDD+ Partnership to "scale up action and finance" that persisted until its closure are exemplary of this. Such disagreements are unlikely to be resolved through a technocratic, managerial approach to bridging fragmentation, as current understandings of bridge organizations in the literature may imply.

We would argue, instead, that securing a "depoliticized" setting should not be the overarching aim (and measure of success) of a bridge organization. Based on our analysis, we conclude that the Partnership has indeed functioned as a valuable enabling organization, one that has partially succeeded in operationalizing a set of enabling, bridging functions in managing a fragmented REDD+ governance landscape. However, its value (and success) derives not, in our view, from having yielded objective information, non-politicized participation, value-free sharing of knowledge, or rational coordination, as a means to generate consensual, technically sound, and apolitical understandings of REDD+. Instead, the very success of a bridge organization such as the Partnership lies in bringing together key actors with divergent notions of what it should achieve. In active engagement with these diverse interpretations, we would argue, lies the transformative potential of such enabling, bridging entities seeking to manage fragmentation in global environmental governance.

Acknowledgments Earlier versions of this article were presented at the 2013 International Studies Association Annual Meeting, Panel on Institutional Complexity in Global Environmental Governance; and at the 2013 Workshop on Fragmentation in Global Environmental Law and Governance, organized by the VUUniversity Amsterdam and Stockholm Environment Institute. We would like to thank David Victor and Lukas Giessen for their detailed commentary on our paper at each event, and Kenneth Abbott, Harro van Asselt, Frank Biermann, Peter Glasbergen, Jessica F. Green, Robert O. Keohane, Philipp Pattberg, Oscar Widerberg, and Fariborz Zelli for useful comments. Special thanks goes to Sabine Reinecke for helpful feedback on earlier drafts of this article. We also thank our interviewees in the UNFCCC and REDD+ Partnership processes for the time taken to respond to our queries, and to Wahida Patwa-Shah of the REDD+ Partnership Secretariat for reading an earlier version of the paper. Finally, we are very grateful to the two anonymous INEA reviewers of our article, whose feedback helped us to strengthen our argument.

17 Interview with representative of CfRN, 12 June 2014, Bonn. 
Open Access This article is distributed under the terms of the Creative Commons Attribution License which permits any use, distribution, and reproduction in any medium, provided the original author(s) and the source are credited.

\section{References}

Abbott, K. (2012). The transnational regime complex for climate change. Environmental Policy and Planning C: Government and Policy, 30(4), 571-590.

Abbott, K., \& Snidal, D. (2006). Nesting, overlap and parallelism: Governance schemes for international production standards. Memo for Alter-Meunier, Princeton Nesting Conference, February 2006. http:// www.princeton.edu/ smeunier/Abbott\%20Snidal\%20memo.pdf. Accessed October 24, 2013.

Aggarwal, V. K. (2005). Reconciling institutions: Nested, horizontal, overlapping, and independent institutions. http://www.princeton.edu/ smeunier/Aggarwal\%20memo.pdf. Accessed October 24, 2013.

Alter, K. J., \& Meunier, S. (2006). Nested and overlapping regimes in the transatlantic banana trade dispute. Journal of European Public Policy, 13(3), 362-382.

Alter, K. J., \& Meunier, S. (2009). The politics of international regime complexity. Perspectives on Politics, 7(1), 13-24.

Berkes, F. (2009). Evolution of co-management: Role of knowledge generation, bridging organizations and social learning. Journal of Environmental Management, 90, 1692-1702.

Betts, A. (2013). Regime complexity and international organizations: UNHCR as a challenged institution. Global Governance, 19, 69-81.

Biermann, F., Pattberg, P., Van Asselt, H., \& Zelli, F. (2009). The fragmentation of global governance architectures: A framework for analysis. Global Environmental Politics, 9(4), 14-40.

Cash, D., Adger, N. W., Berkes, F., Garden, P., Lebel, L., Olsson, P., et al. (2006). Scale and cross-scale dynamics: Governance and information in a multilevel World. Ecology and Society, 11(2), 8-18.

Cerbu, G. A., Swallow, B. M., \& Thomson, D. Y. (2011). Locating REDD: A global survey and analysis of REDD readiness and demonstration activities. Environmental Science \& Policy, 4(2), 168-180.

Convention on Biological Diversity, (CBD). (2015). http://www.cbd.int/. Accessed March 9, 2015.

Crona, B. I., \& Parker, J. N. (2012). Learning in support of governance: Theories, methods and a framework to assess how bridging organizations contribute to adaptive resource governance. Ecology and Society, 17(1), 32.

Davis, C., \& Daviet, F. (2010). Investing in results: enhancing coordination for more effective interim REDD+ financing. WRI Working Paper. World Resource Institute, Washington DC. http://www.wri. org/publication/investing-in-results. Accessed May 12, 2013.

Drezner, D. W. (2009). The power and peril of international regime complexity. Perspectives on Politics, $7(1), 65-70$.

Folke, C., Hahn, T., Olsson, P., \& Norberg, J. (2005). Adaptive governance of social-ecological systems. Annual Review of Environment and Resources, 30, 441-473.

Gehring, T., \& Oberthür, S. (2004). Exploring regime interaction: A framework of analysis. In A. Underdal \& O. R. Young (Eds.), Regime consequences: Methodological challenges and research strategies. The Netherlands: Springer.

Gupta, A. (2008). Transparency under scrutiny: Information disclosure in global environmental governance. Global Environmental Politics, 8(2), 1-7.

Gupta, A. (2010a). Transparency to what end? Governing by disclosure through the biosafety clearing house. Environment and Planning C: Government and Policy, 28(1), 128-144.

Gupta, A. (2010b). Transparency in global environmental governance: A coming of age? Global Environmental Politics, 10(3), 1-9.

Gupta, A., Lövbrand, E., Turnhout, E., \& Vijge, M. J. (2012). In pursuit of carbon accountability: The politics of REDD+ measuring, reporting and verification systems. Current Opinion on Environmental Sustainability, 4(6), 726-731.

Gupta, A., Vijge, M. J., Turnhout, E., \& Pistorius, T. (2014). Making REDD+ transparent: The politics of measuring, reporting and verification systems. In A. Gupta \& M. Mason (Eds.), Transparency in global environmental governance. Cambridge: MIT press.

Herold, M., \& Skutsch, M. (2011). Monitoring, reporting and verification for national REDD+ programmes: Two proposals. Environmental Research Letters, 6, 1-10.

IPCC. (2003). Good practice guidance for land use, land-use change and forestry. www.ipcc-nggip.iges.or. jp/public/gpglulucf/gpglulucf.htm. Accessed 3 July 2013. 
Keohane, R., \& Victor, D. (2011). The regime complex for climate change. Perspectives on Politics, 9(1), 7-23.

La Viña, T., \& Lee, D. (2014). Assessment of the results of the REDD+ Partnership. http://www.fao.org/ partnerships/redd-plus-partnership/en/. Accessed March 9, 2015.

Lang, C. (2010a). How the REDD+ Partnership unraveled in Tianjin. http://www.redd-monitor.org/2010/ 10/12/how-the-redd-partnership-unravelled-in-tianjin/. Accessed November 24, 2014.

Lang, C. (2010b). NGO letter to the Interim REDD+ Partnership raises fundamental questions. http://www. redd-monitor.org/2010/09/10/ngo-letter-to-the-interim-redd-partnership-raises-fundamental-questions/. Accessed December 8, 2010.

Lang, C. (2014). The dismal failure of the REDD+ Partnership. http://www.redd-monitor.org/2014/11/20/ the-dismal-failure-of-the-redd-partnership/. Accessed November 24, 2014.

McDermott, C. L., Coad, L., Helfgott, A., \& Schroeder, H. (2012). Operationalizing social safeguards in REDD+: Actors, interests and ideas. Environmental Science \& Policy, 21, 63-72.

McMullen, R. S., \& Adobor, H. (2011). Bridge leadership: A case study of leadership in a bridging organization. Leadership \& Organization Development Journal, 32(7), 715-735.

Moss, N., Nussbaum, R., Muchemi, J., \& Halverson, E. (2011). A review of three REDD+ safeguard initiatives. UN-REDD Programme \& Forest Carbon Partnership Facility. http://www.un-redd.org/ PublicationsResources/tabid/587/Default.aspx\#joint_publications

Oberthür, S. (2009). Interplay management: Enhancing environmental policy integration among international institutions. International Environmental Agreements, 9, 371-391.

Orsini, A., Morin, J.-F., \& Young, O. (2013). Regime complexes: A buzz, a boom or a boost for global governance? Global Governance, 19, 27-39.

Pistorius, T. (2012). From RED to REDD+: The evolution of a forest-based mitigation approach for developing countries. Current Opinion in Environmental Sustainability, 4(6), 638-645.

Pistorius, T., \& Reinecke, S. (2013). The interim REDD+ Partnership: Boost for biodiversity safeguards? Forest Policy and Economics, 36, 80-86.

Raustiala, K., \& Victor, D. G. (2004). The regime complex for plant genetic resources. International Organization, 58(2), 277-309.

REDD+ Partnership (2010a). Founding document. http://www.oslocfc2010.no/pop.cfm?FuseAction= Doc\&pAction=View\&pDocumentId=25019. Accessed October 22, 2013.

REDD+ Partnership (2010b). Interim REDD+ Partnership. Modalities of Stakeholder Participation. Tianjin, October. http://reddpluspartnership.org/23477-072817a5ccf72c2071aa1da88ca5a294e.pdf. Accessed October 24, 2013.

REDD+ Partnership (2014). Meeting and workshop, 27-28 November, 2014, Peru, Lima. http:// reddpluspartnership.org/73943/en/. Accessed December 11, 2014.

Reinecke, S., Pistorius, T., \& Pregernig, M. (2012). UNFCCC and the REDD+ Partnership from a networked governance perspective. Environmental Science \& Policy,. doi:10.1016/j.envsci.2012.09.015.

Ritter, D. (2012). Whatever happened to the REDD+ Partnership? Global Policy blog. http://www. globalpolicyjournal.com/blog/01/03/2012/whatever-happened-redd-partnership. Accessed December 3, 2014.

Streck, C. (2012). Financing REDD+: Matching needs and ends. Current Opinion in Environmental Sustainability, 4(6), 628-637.

UNFCCC (2013). Report of the Conference of the Parties on its nineteenth session, held in Warsaw from 11 to 23 November 2013. Addendum. Part two: Action taken by the Conference of the Parties at its nineteenth session. Contents. Decisions adopted by the Conference of the Parties. FCCC/CP/2013/10/ Add.1.

Van Asselt, H., \& Zelli, F. (2012). Connect the dots: Managing the fragmentation of global climate governance. Earth System Governance Working Paper no. 25. Lund and Amsterdam: Earth System Governance Project.

Visseren-Hamakers, I. J., Arts, B., \& Glasbergen, P. (2011). Interaction management by partnerships: The case of biodiversity and climate change. Global Environmental Politics, 11(4), 89-107.

Visseren-Hamakers, I. J., Gupta, A., Herold, M., Peña-Claros, M., \& Vijge, M. J. (2012a). Will REDD+ work? The need for interdisciplinary science to address key challenges. Current Opinion in Environmental Sustainability, 4(6), 646-653.

Visseren-Hamakers, I. J., McDermott, C., Vijge, M. J., \& Cashore, B. (2012b). Trade-offs, co-benefits and safeguards: Current debates on the breadth of REDD+. Current Opinion in Environmental Sustainability, 4(6), 590-596.

Visseren-Hamakers, I. J., \& Verkooijen, P. (2013). The practice of interaction management: Enhancing synergies among multilateral REDD+ institutions. Forest and Nature Governance World Forests, 14, 133-149. 
Wertz-Kanounnikoff, S., \& Kongphan-Apirak, M. (2009). Emerging REDD+: A preliminary survey of demonstration and readiness activities. Working Paper 46. Bogor: CIFOR.

Young, O. R. (1996). Institutional linkages in international society: Polar perspectives. Global Governance, 2(1), 1-24.

Zelli, F., Gupta, A., \& Van Asselt, H. (2013). Institutional interactions at the crossroads of trade and environment: The dominance of liberal environmentalism? Global Governance, 19, 105-118.

Zelli, F., \& Van Asselt, H. (2013). Introduction: The institutional fragmentation of global environmental governance: Causes, consequences, and responses. Global Environmental Politics, 13(3), 1-13. 